\title{
SELÇUKLULAR VE TÜRKÇE
}

\section{ERDOĞAN MERÇIL}

Zaman zaman Türk hükümdarlarının hâkim oldukları ülkeler nedeniyle anadillerini muhafaza edip etmedikleri tereddütlere yol açmışur. Bazı araştırıcılar Selçuklular döneminde sarayda ve orduda Türkçe konuşulduğunu kabul etmelerine rağmen bu konuda yeterli deliller ortaya koyamamışlardır ${ }^{1}$. Bazı araşturıcılar ise Türkçe'nin kullanımını edebî eserlerle açıklamaya çalışmışlardır. Bu tebliğimizde Selçuklu hükümdarları ve orduda Türkçe konuşulması hakkında bazı destekleyici bilgiler ortaya koyarak, bu konuya bir ölçüde açıklık getirmeye çalışacağız. Ancak Selçuklular'dan önce onların sık sık temasda bulundukları ve devlet teşkilâtı konusunda etkilendikleri Gazneli sultanların Türkçe konuştukları hakkında bazı bilgiler vermek faydalı olacaktur.

Gazneliler döneminde Türkçe konuşmayla tespit edebildiğimiz ilk bilgi hanedanın kurucusu Sebüktegin (977-997) ile başlamaktadır. Hurma yetiştiren bir köylü, hurmalarını alıp götüren bir filci (filbân) den şikâyetçi olmuştu. Sebüktegin hemen harekete geçmiş ve bu sırada yanında bulunan (Harezmşah) Altuntaş'a Türkçe olarak, "yayın kirişini çıkar, önce file sonra da ağaca doğru yürü ve filciyi bu kirişle as" diye emir vermişti². Sultan Mahmûd (998-1030)'un askerleri Karahanlılarla yapılan savaşların birinde, "Hoten'de bestelenmiş" Türkçe bir şarkı söylemişlerdi ${ }^{3}$. Sultan Mes'ûd (1030-1040) ise, herkesin duymasını istemediği emirleri bazen Türkçe olarak vermekte idi ${ }^{4}$. Dandanakan Savaşı (1040) sırasında Gazneli ordusu mağlup olup dağıldığı sırada Mes'ûd hâlâ mücadele etmekte ve neredeyse esir düşmek üzere idi. Nitekim bir saray görevlisi Câmedâr Hacib Türkçe olarak,

${ }^{1}$ Bk. M. A. Köymen, Büyük Selçuklu İmparatorluğu Tarihi, III, Alp Arslan ve Zamanı, Ankara 1992, s. 235; O. Turan, Selçuklular Tarihi ve Türk-İslâm Medeniyeti. Ankara 1965. s. 312,318 .

${ }^{2}$ Hace Ebu'l-Fazl Muhammed b. Huseyn Beyhakî, Tarih-i Beyhakî (nşr. Gani-Feyyaz), Tehran hş. 1324, s.450.

${ }^{3}$ Bk. V.V. Barthold, Moğol Istilâsına Kadar Türkistan (Haz. H. D. Yildız), Ankara 1990, s. 292.

${ }^{4}$ Bk. Beyhakî, s. 163, 166, 438. 
"Emîr acele gitmezse düşman eline düşecek" demişti. Sultan bunun üzerine durumun vahametini anlayarak savaş meydanını terketmişti ${ }^{5}$. Sultan Mes'ûd'un veziri Ahmed Abdüssamed de Türkçe bilmekte idi ${ }^{6}$. Öte yandan Sultan Mahmûd ve Mes'ûd dönemlerinin ileri gelen kumandanlarından Sipehsâlâr Gazi ve Eryaruk zaman zaman içki meclisleri tertip ediyorlardı. İçki meclisine katulan Türkler bu iki kumandanı Türkçe methediyorlardı ${ }^{7}$.

Dandanakan Savaşı'nın kazandıktan sonra Selçuklular kendi aralarında toplandılar, (artık) zengin olmuşlardı. Çünkü, yağmadan elde ettiklerinin haddi ve hesabı yoktu. Hiç kimse karşılarında söz söylemeye cesaret edemiyordu. Onlar Türkçe olarak "bunu biz yaptık" diyorlardı ${ }^{8}$. Selçuklular döneminde Türkçe konuşan hanedan mensupları hakkındaki tespitlerden biri İbrahim Yınal (öl.1059) ile ilgilidir. Arslan Besasirî ile işbirliği yapmış olan Ukayliler'den Kureys ve Mezyedîler'den Dübeys, Sultan Tuğrul Bey (10381063) 'den aff dilemişlerdi. Daha sonra İbrahim Yınal'ın karşı harekete geçmesi üzerine, onlar Vezir Amid el-Mülk'e bir mektup yazarak durumu bildirdiler ve yardım istediler. Bu olaydan haberdar olan İbrahim Yınal, Vezir Amid el-Mülk'e Türkçe "Araplarla sultanın arasını buldun mu? Onlanı barışa razı ettin mi? Ancak barış birbirine eşit kimseler arasında olur..." şeklinde hitap etti. Amid el-Mülk'ün cevabından sonra, İbrahim Yınal ona, "Bugün çadırına git, dinlen ve istirahat et. Yarın sultanla bir araya gelirsin" dedi ${ }^{9}$.

Tuğrul Bey 24 Ocak 1058'de Halife Kaim bi-Emrillah ile buluştuğu zaman, halife reisürrüesa'ya, "Sultan Rükneddîn Tuğrul Bey'i kendisine doğru, onun konuşmalarını tercüme ve açıklaması için de Vezir Kündürî̀yi onun hemen yakınına oturt" emrini verdi. Böylece her ikisi, istenilen şekilde oturdular. Amid el-Mülk Kündürî daha sonra halifenin sözlerini sultana aynen tercüme etti ${ }^{10}$.

${ }^{5}$ Bk. aynı eser, s. 624. Krş. M.A. Köymen, Büyük Selçuklu Imparatorluğu Tarihi,I,Kuruluş Devri, Ankara 1979, s. 339.

${ }^{6}$ Bk. Beyhakî, s. 655 .

${ }^{7}$ Bk. Beyhakî, s. 222.

${ }^{8}$ Bk. Beyhakî, s. 628 . Ancak Gani-Feyyaz bu ifadenin yanlış olduğunu belirtiyorlar bk. 628 not. 5. Köymen (Kuruluş Devri,s. 344) Sa'id Nefisî neşrini kullanarak, Beyhakî'yi bizim belirttiğimiz şekilde tercüme etmiştir.

${ }^{9}$ Bk. 'Sıbt İbnü'l-Cevzi'nin Mir'atū'z-Zaman Fì Tarihi'l-Âyan adlı eserindeki Selçuklular İlgili Bilgiler, I., Sultan Tuğrul Bey Dỏnemi", Ali Sevim, Belgeler, Sayı: 22, Ankara 1997, s. 22.

10 Bk. aynı eser, s.27.; el-Bundarî, Zubdet el-Nusra ve Nuhbet el-'Usra, Arapça metin, s.14/Trk.trc. Kıvameddin Burslan, Irak ve Horasan Selçukluları Tarihi,İstanbul 1943, s. 11. 
Halife Kaim bi-Emrillah, Arslan Besasirî'nin elinden kurtulduktan sonra, Tuğrul Bey yine halife ile buluşmuştu (Ocak 1060). Bu buluşmada Tuğrul Bey, Büveyhoğulları'na âit olan örülmüş kırmızı yakut ipi çıkardı ve halifenin önüne att, sonra da oniki büyük ve değerli, sekizer köşeli incileri çıkarup, "Bunlar Arslan Hatun'un armağanıdır, o bunları benimle size gönderdi ve emîr el-müminine bunları tespih yapmasını bildirmemi benden istedi" dedi. Sultan bunları tercüme etmesi için Amid el-Mülk'e Türkçe söylemişti ${ }^{11}$. Bu olaylardan Vezir Amid el-Mülk'ün de ana dili olan Farsça'dan başka Türkçe'yi de bildiği anlaşllıyor ${ }^{12}$. Nitekim İbn Hassul Türkler hakkında yazmış olduğu Tafzîl el-Etrak âlâ sâ'ir el-ecnâd başlıklı eserini Selçuklu veziri Amid el-Mülk'e takdim ve Tuğrul Bey'e okumasını rica ederek onun için demişti; "..Kitabımı Tuğrul Bey'e... Türkçe tefsir ve izah edecektur"12a.

Tuğrul Bey döneminde Türkçe'yle ilgili son tespitimiz, sultan ve halifenin kızı Seyyide'nin düğünü münasebetiyledir (1063). Bu düğün sırasında Selçuklu devlet adamları ve sultanın yakınları sevinçlerinden oynayıp Türkçe şarkılar söylüyorlardı ${ }^{13}$. Bir diğer rivayete göre ${ }^{14}$, sultan da Türk eşrafı ile ayağa kalkarak kendi âdetlerine uygun olarak raksetmiş... ve Türk şarkıları söylemişti.

Sultan Alp Arslan (1063-1072)'ın Türkçe konuştuğu hakkında -şimdilikbir bilgi tespit edilmemiştir. Ancak Malazgirt Savaşı'yla ilgili olarak zikredilen olaylarda kaynaklar sultanın çeşitli konuşmalar yapuğını belirtiyorlar. Nitekim İbn el-Esir'e göre ${ }^{15}$, sultan savaş başlamadan önce askerlerine şöyle demiştir, "Ben Allah rızası için sabrederek savaşacağım, sağ kalırsam bu Tanrı'nın bana bir lütfudur, şehit olursam oğlum Melikşah benim halefimdir”. Alp Arslan'ın savaş başlamadan önce askerlerine ve kumandanlarına buna

${ }^{11}$ Bk. Stbt, aynı eser, s. 52.

${ }^{12}$ Köymen'e göre (Alp Arslan ve Zamanı, III, s. 157), Amid el-Mülk Farsça, Türkçe, Arapça ve Hindu dilini biliyordu.

${ }^{12 a}$ Bk. Abbas Azzavi, "İbn Hassul'un Türkler Hakkunda Bir Eseri", Türkçeye çeviren Şerefeddin Yaltkaya, Belleten sayn: 14-15. Ankara 1940, Arapça metin, s. 45. s. 247, 262.

${ }^{13}$ Bk. Sibt, ayn eser, s.82-83.

${ }^{14}$ Bk. Gregory Abu'l Farac (Bar Hebraeus), Abu'l Farac Tarihi, I, Trk.trc. Ömer R. Doğrul, Ankara $1987^{2}$, s. 315. Krş. Turan, Selçuklular Tarihi, s. 94.; M.A. Kōymen, Tuğrul Bey ve Zamani,İstanbul 1976, s. 120.

${ }^{15}$ Bk. İslâm Tarihi,El-Kâmil Fi't-Târih Tercümesi,çvr. A. Özaydın, I cilt, İstanbul 1987, s. $71-72$. 
benzer hitapları ve Bizans İmparatoru Romanos Diogenes arasındaki meşhur görüşmesi ${ }^{16}$, acaba hangi dilde olmuştur?.

Öte yandan Malazgirt Savaşı esnasında Uzlar ve Peçenekler, Selçuklu Türkleriyle karşılaştıkları zaman onların soydaşları olduğunu kılık kıyafet ve konuşmalarından anlayarak savaşın başında Selçuklular'ın tarafina geçmişlerdi ${ }^{17}$.

Sultan Alp Arslan bir içki meclisinden sonra sarhoş olduğu zaman, daha önce kendisine itaat eden Haleb Mirdasî Emîri Mahmûd'u öldürmek istediğinde Vezir Nizâm ül-Mülk ve sultanın hatunu onu engellemişlerdi ${ }^{18}$. Bu olaya sırasında Alp Arslan, hatunu ve Nizâm ül-Mülk hangi dilde konuşmuştur?. Bunlar yoruma açık, fakat kanıt isteyen konuşmalardır ${ }^{19}$.

Sultan Melikşah (1072-1092)'ın Türkçe mektup yazdığı hususundaki bilgi ise oldukça dikkat çekicidir. Melikşah'ın nedimlerinden biri Divan ülinşâ sahibi Kemâleddîn Ebu'r-Rıza Fazlullah b. Muhammed idi. Bu şahıs sultanın çok teveccühünü kazanmış olup, daima huzurda bulunurdu. Bir gün bir engel çıkmış ve Kemâleddîn sultanın yanına gidememiş idi. Melikşah kendisine Türkçe olarak, "Sen bensiz olabilirsin, fakat ben sensiz olamam..." mealinde bir mektup yazdı ${ }^{20}$ (Feketebe ileyhi bi't-Türkiyye). Sultan Türkçe mektup yazdığına göre acaba hangi harfleri kullanmıştu?. Bu da çözüm bekleyen olaylardan biriyse de, daha sonra bazı Türkçe kelime ve cümleciklerin kaynaklarda Arap harfleriyle yazılması konuya bir ölçüde açıklık getirmektedir.

Türkçe konuştuğunu tespit ettiğimiz sultanlardan biri de Muhammed Tapar (1105-1118) idi. Sultan Berkyaruk öldükten sonra (1104), küçük yaş-

\footnotetext{
${ }^{16} \mathrm{Bk}$. İslâm Kaynaklarına göre Malazgirt Savaşı (metinler ve çevirileri), F. Sümer-A.Sevim, Ankara 1971.

17 Bk. Urfalı Mateos Vekayi-Nâmesi (952-1136) ve Papaz Grigor'un Zeyli (11361162),Trk.çvr. Hrant D. Andreasyan, Ankara 1962, s. 143. Krş. I. Kafesoğlu, Malazgirt (Malazgirt muharebesi) mad., IA., s. 246.; Köymen, Alp Arslan ve Zamanı, III, s. 34.

${ }^{18}$ Bk. Biyografilerle Selçuklu Tarihi, İbnü'l-Adîm Bugyetü't-Taleb fí Tarihi Haleb (Seçmeler), çeviri notlar ve açıklamalar, Ali Sevim, Ankara 1982, s. 18.

${ }^{19}$ Nizâm ül-Mülk'ün Türkler'den oluşan binlerce kölesi olduğuna gōre (bk. İbn el-Esir, Trk. Trc. X, s. 123), onlarla nasıl anlaşıyordu? Bu konuyu ve Gazneliler'den itibaren Türkler'in hizmetinde bulunduğunu dikkate alırsak büyük bir ihtimalle onun da Türkçe bildiğini òne sürebiliriz.

${ }^{20}$ Sadruddin Ebu'l-Hasan Ali b. Nâsır İbn Ali el-Hüseynî, Ahbâr üd-Devlet is-Selçukiyye, nşr. Muhammed Ikbal, Lahor 1933, s. 68-89./Trk.trc. N. Lügal, Ankara 1943, s. 47, (Feketebe ileyhi bi't-Türkiyye). Krş. Turan, Selçuklular Tarihi, s. 318.
} 
taki oğlu Melikşah, Bağdat'da sultan ilân edildi ve Emîr Ayaz da kendisine "atabeg" oldu. Muhammed Tapar da derhal Bağdat'a yürüdü. Atabeg Ayaz da Muhammed Tapar ile anlaşmayı tercih ederek onun sultanlığını tanımışt. Ayaz daha sonra büyük bir ziyafet hazırlayıp Sultan Muhammed Tapar'ı davet etti. Ancak kötü bir tesadüf eseri ziyafet sırasında kölelerin şakalaşmaları sonucu bir kâtip sultanın yakın adamlarına sığınmışt. Sultan bu durumdan şüphelenmiş ve bir kölesine Türkçe olarak, hiçbir kimseye bildirmeden o şahsın üzerinde ne var diye tutup bakmasını emretmişti (25 Şubat 1105$)^{21}$.

Suriye Selçuklu Meliki Tutuş (1078-1095) da Türkçe konuşan Selçuklular'dan biridir. O Anadolu fatihi Süleyman-şah ile Haleb hâkimiyeti için savaşmıştı. Bu savaş sonunda (4 Haziran 1086), Süleyman-şah hayatına son vermişti. Tutuş, onun cesedini teşhis ettikten sonra,Türkçe "biz sizlere zulmettik, sizleri bizden uzaklaşturdık ve işte böyle de öldürüyoruz" demişti ${ }^{22}$.

Sultan Sencer döneminde (1118-1157), "Togan Bey menşei Türk, bu bakımdan Türkçe bildiği ... için" sultanın mizacına tasarruf etmiş, böylece vezir tayin edilmişti ${ }^{23}$. Sultan Sencer'in konar-göçer Oğuzlar'in elinde esir kaldığı süre içinde (1153-1156) onlarla Türkçe konuştuğu şeklindeki yorumumuz muhtemelen yanlış olmayacakur.

Irak Selçukluları zamanında ise Türkçe konuşmayla ilgili olarak hemen hemen hiç bilgi yoktur. Sultan Mahmûd (1118-1131)'a karşı, Atabag Çavuş'un da desteğiyle, kardeşi Mes'ûd isyan etmişti. İki ordu savaşa başladığında Mes'ûd, Mahmûd'u gördüğü zaman "İci ici” diye bağırmıștı. Kaynağın ifadesiyle, "Bu Türkçe büyük kardeş, yani ağabey demektir"24 (14 Haziran 1120).

Türkiye Selçukluları döneminde de biraz yorum ile Türkçe konuşulduğunu ileri sürebiliriz. Bu örneklerden biri Hacib Zekeriya ile ilgilidir. Sultan II. Sülayman-şah'ın ölümünden (1204) sonra, Selçuklu emîrleri Gıyaseddîn

${ }^{21}$ Bk. İbn el-Esir, Trk.trc. X, s. 314. Olay için bk. A. Özaydın, Sultan Muhammed Tapar Devri Selçuklu Tarihi (498-511/1105-1118), Ankara 1990, s. 43.

${ }^{22}$ Bk. A. Sevim, Suriye ve Filistin Selçuklulan Tarihi, Ankara 1983, s. 124.

${ }^{23}$ Bk. Seyf el-Dîn Hâcı b. Nizâm Ukaylî, Âsâr el-Vüzerâ, nşr. Mir Celâl el-Dîn Hüseynî Urmevî, Tehran hş. 1337, s. 236; Handmîr, Düstûr el-Vüzerâ, nşr. Sa'îd Nefisî, Tehran hṣ. 1317, s. 191. Krş. A. Taneri, "Büyük Selçuklu İmparatorluğu'nda Vezirlik", TAD, V, Ankara 1970, s. 96.

${ }^{24}$ Bk. Ahbâr, Arapça metin, s. 96-97/Trk.trc. s. 68; Bundarî, Arapça, s. 132-133/Trk.trc. s. $126-127$. 
Keyhusrev'i tahta davet etmek için Zekeriya'yı İstanbul'a gönderdiler. İbn Bibî'ye göre ${ }^{25}$, "Hacib Zekeriya Rum ülkesinde (Anadolu) halkın konuştuğu beş dile tam hâkimiyet sağlamıs, o dilleri inceliklerine ve ayıntılarına kadar öğrenmişti”. Bu beş dilden biri muhakkak Türkçe olmalıdır. Nitekim Yazıcızâde ${ }^{26}$, İbn Bibî'nin bu ifadesini "Türkî ve Parsiden gayri beş dil bilürdi ki Anadolu'da ve Rum-İli'nde söylenirdi ..." şeklinde aksettiriyor. Rahmetli Prof. Dr. Osman Turan ${ }^{27}$, bu dönemde konuşulan dillerden dördünü Türkçe, Rumca, Ermenice, büyük şehir ve kültür çevresinde Farsça olarak zikrediyor. Beşinci dil konusunda ise mütereddittir. En az üç dilin desteklendiği bir olay ise, Sultan Celâleddîn Harezmşah'ın Ahlat kuşatması sırasında yaşanmıştur. Ahlat'tan Sultan Celâleddîn'in huzuruna gelen yaşlı bir kadın Arapça, Türkçe ve Ermenice biliyordu ${ }^{28}$.

I. İzzeddîn Keykavus döneminde (1210-1219) sultan Ermeniler'in sahip olduğu Hancin kalesine bir sefer tertibledi. İzzeddîn Keykavus burada savaş için emir vermiş ve çavuşlar Türkçe "Atlan atlan" diye bağırmışlardı. İbn $B i \hat{A}^{29}$, sultanın bu emrini Arap harfleri ile Türkçe olarak aynen eserinde yazmışur ( اطلان اطلان ).

Sultan I. Alâeddîn Keykubad (1219-1237), huzuruna gelen Harezmşah Celâleddîn'in elçilerine tercüme istemeden hitap etmişti ${ }^{30}$. Burada sultan tercüman istemediğine göre elçilerle Türkçe konuşmuş olmalıdır ${ }^{31}$. Alâeddîn Keykubad Harezmşah'a karşı işbirliği yaptğı Melik Eşref ile konuştuğu sırada Emîr Kemâleddîn Kamyar tercümanlık yapmış̦t ${ }^{32}$. Bu olayda Emîr Kemâleddîn, Arapça konuşan Melik Eşref' in sözlerini Türkçe'ye çevirmiştir. İbn Bibî ${ }^{33}$, Sultan Alâeddîn Keykubad'ın faziletlerinden söz ederken onun rubailer söylediğini zikrediyor. Yazıcı-zâde ${ }^{34}$ ise şöyle bir ilavede bulunuyor,

${ }^{25}$ Bk. el-Evâmirü'l-'Ala'iye fi'l-Umûr il'Alâ'iya, nşr. A. S. Erzi, I, Tıpkıbasım, Ankara 1956. s. 77/ Türkçe trc. Mürsel Öztürk, Ankara 1996, I, s. 97.

${ }^{26}$ Bk. M.Th. Houtsma, Recueil de Textes relatifs a' l'historie des Seljoucides, Histoire Des Seldjoucides D'Asie Mineure D'Abres İbn-Bibi Texte Turc, III, Leiden 1902, s. 63.

${ }^{27}$ Bk. Selçuklular Zamanında Türkiye, İstanbul 1971, s. 272.

${ }^{28} \mathrm{Bk}$. Muhammed Nesevî, Siret-i Celâl el-Dîn Mingburnı, nşr. Mücteba Minovi, Tehran hş. 1344 , s 208 .

${ }^{29}$ Bk. Farsça metin, s. 166/Trk. Trc. S. 381-382.

${ }^{30}$ Bk. İbn Bibî, s. 376/Trk.trc.s. 381-382.

${ }^{31}$ Celâleddîn Harezmşâh da Türkçe konuşmakta idi (...Turkî guy), Nesevî, s. 281.

${ }^{32}$ Bk. İbn Bibî, 387/Trk.trc., I, S. 390.

${ }^{33}$ Bk. Farsça metin, s. 228/Trk.trc., s. 246.

${ }^{34}$ Bk. s. 216. 
"Her çend ki Türkî el-asl ve Oğuz sultanlarındandı amma çün ol vakt ki dahi Türkî şiir yogdu ve Acem ikliminden gelmişlerdi, ekser evkat Farsî söylerlerdi". Böylece Yazıcı-zâde de edebiyat alanında Farsça'nın hâkim olduğunu kabul ediyor. Ancak Selçuklular'ın Türk asıllı olduklarını belirterek geri plânda belki de Türkçe konuştuklarını îma ediyor?.

Türkiye Selçuklu sultanı IV. Kılıç Arslan (1257-1265) aralarında anlaşmazlık bulunan Muineddîn Pervane'ye "İci mesti veya mahşuşi/Ağabey sarhoş musun veya uyuşturucu mu aldın?" şeklinde hitap etmişti ${ }^{35}$ (1266). Daha önce 1120 'lerde karşılaştı̆ımız Türkçe ici kelimesi aşağı-yukarı birbuçuk yüzyıl sonra Anadolu'da varlığını sürdürüyor ve kullanılıyordu.

Türkiye Selçukluları çöküş döneminde olmasına rağmen Türkçe konusunda önemli bir gelişme 1277 yllında görüldü. Moğollar'ın Anadolu'ya hâkim olmasından sonra buraya yeni gelen Türkmen boyları ile Türkçe konuşanların sayısında muhakkak aruş olmuştur. Nitekim Türkmenler'in desteklediği Alâeddîn Siyavuş (Cimri) Selçuklu tahtına oturmuş ve ertesi günü Konya'da toplanan Selçuklu divanı Türkçe'nin resmî dil olması yönünde önemli bir karar almışu (13 Mayıs 1277) ${ }^{36}$.

Öte yandan Anadolu'ya hâkim olan Moğol hükümdarlarının ve halkın Türkçe konuştuğu hususunda bir örnek tespit edebiliyoruz. Geyhatu (12911295) Ilgın yöresinde bir çiftçiye buğday tohumu ekerken yardımda bulunmuş ve Türkçe olarak, "Yükü beş akçaya yükü beş akçaya/ يكى بيش اتجيا يكى بيش اتجيا "demişti" (1291).

Netice olarak;

a) Büyük Selçuklular döneminde sarayda ve orduda Türkçe konuşulduğunu rahatlıkla tespit edebiliyoruz,

b) Bürokratlar arasında da Türkçe konuşanlar mevcuttur.

c) Türkçe; Türkiye Selçukluları zamanında da varlığını sürdürmüş, Beylikler ve Osmanlılar döneminde Anadolu'da hâkim dil olmuştur.

${ }^{35}$ Bk. Aksaraylı Mehmed oğlu, Kerimüddin Mahmûd, Müsamaret ül-Ahbâr,Moğollar Zamanında Türkiye Selçukluları Tarihi, nşr. O. Turan, Ankara 1944, s. 85 ve not 3 /Trk.trc. M. Öztürk, Ankara 2000, s. 65. Krş. N. Kaymaz, Pervàne Mu'înü'd-Dîn Süleyman, Ankara 1970, s. 120.

${ }^{36}$ Bk. E. Merçil, 'Türkiye Selçukluları Devrinde Türkçe'nin Resmî Dil Olmasını Kim Kabul Etti?", Belleten, Sayn: 239, Ankara 2000, s.51-57.

${ }^{37}$ Farsça Anonim Selçuk-nâme, nşr.F.N.Uzluk, Anadolu Selçuklulanı Devleti Tarihi, III, Ankara 1852, s.80.; Turan, Müsameret ül-Ahbàr, ònsōz. s. 24. 
